\title{
An analysis of interdecadal variations in the perturbational feedback parameter based on a MIROC6 piControl simulation
}

Ko Tsuchida ( $\nabla$ tsuchida.kou.070@s.kyushu-u.ac.jp )

Kyushu University: Kyushu Daigaku https://orcid.org/0000-0001-8605-0233

Takashi Mochizuki

Kyushu University: Kyushu Daigaku

Ryuichi Kawamura

Kyushu University: Kyushu Daigaku

Tetsuya Kawano

Kyushu University: Kyushu Daigaku

\section{Research Article}

Keywords: Climate sensitivity, Internal variation, ENSO, Background field, Decadal variation

Posted Date: September 16th, 2021

DOI: https://doi.org/10.21203/rs.3.rs-904989/v1

License: (a) (i) This work is licensed under a Creative Commons Attribution 4.0 International License.

Read Full License 
4 Ko Tsuchida ${ }^{1}$

5 Corresponding author

$6 \quad$ Email: tsuchida.kou.070@s.kyushu-u.ac.jp

8 Takashi Mochizuki ${ }^{1}$

9 Email: mochizuki.takashi.817@m.kyushu-u.ac.jp

Ryuichi Kawamura $^{1}$

Email: kawamura.ryuichi.130@m.kyushu-u.ac.jp

Tetsuya Kawano ${ }^{1}$

Email: kawano.tetsuya.942@m.kyushu-u.ac.jp

(Institutional address)

$18{ }^{1}$ Department of Earth and Planetary Sciences, Faculty of Science, Kyushu University, 744 Motooka, Nishi, Fukuoka, Fukuoka, 819-0395, Japan

\section{Abstract}

The climate feedback parameter is a useful indicator for estimating climate sensitivity relating to anthropogenic forcing. This study defines a new feedback parameter, the Perturbational Feedback Parameter (PFP), and the impacts of internally-generated climate variations are clarified using the MIROC piControl simulation. PFP values are found to vary significantly on interdecadal timescales. The equatorial sea surface temperature (SST) has a positive anomaly in the eastern Pacific and a negative anomaly in the western Pacific, and the thermocline tilts more gently than usual when the PFP is large. The statistical properties of the interannual fluctuations also simultaneously vary, and they correspond to the background state. For example, there is an increase in the El Niño Southern Oscillation (ENSO) amplitude relative to the global mean surface temperature rise, and the equatorial high SST more effectively contributes to the southward shift of the Intertropical Convergence Zone (ITCZ). In addition, a decadal fluctuation that dominates over the extratropical northern Pacific also plays an important role in PFP variations. These fluctuations on broad timescales cooperatively induce increases in lower clouds within the subtropics by strengthening the descending flow and static stability, and the consequential net downward radiation flux change through increases in reflection enhances the PFP. In summary, internal changes in both tropical and extratropical variability corresponding to the background state control the strength of the climate feedback on interdecadal timescales. 
Keywords: Climate sensitivity, Internal variation, ENSO, Background field, Decadal variation

1. Introduction

Understanding the climate response to external forcing, such as anthropogenic forcing, is crucially important for projecting and evaluating the future climate. The concept of climate sensitivity relates to how the climate system responds to external forcing, such as greenhouse gases and aerosols. Equilibrium climate sensitivity (ECS) is one of the most widely used forms of climate sensitivity, and it is defined as the change in the steadystate global-mean surface air temperature that will eventually occur in relation to a doubling of the $\mathrm{CO}_{2}$ concentration. ECS is not only applied in IPCC, but it is also a convenient indicator used to compare the climate system responses of several general circulation models (GCMs) (Kunutti and Hegerl 2008; Andrews et al. 2012; Gregory et al. 2020).

Processes in a climate system that can either amplify or dampen the climate system response to an external perturbation are referred to as climate feedback (Bony et al. 2006). In estimating the values of climate sensitivity and climate feedback, a simplified energy balance concept is generally used, as shown by the equation below,

$$
N=F-R=F-\alpha T,
$$

where $N$ is the net downward radiation flux (positive downward) change at the top of the atmosphere $\left[\mathrm{W} / \mathrm{m}^{2}\right]$, $F$ is the external forcing $\left[\mathrm{W} / \mathrm{m}^{2}\right]$ affecting the climate system (positive downward), $R$ is the climate radiative response $\left[\mathrm{W} / \mathrm{m}^{2}\right]$ connected to the change in surface temperature $T[\mathrm{~K}]$ (positive upward), and $\alpha$ is the climate feedback parameter $\left[\mathrm{W} / \mathrm{m}^{2} / \mathrm{K}\right]$ (Gregory et al. 2004; Gregory and Webb 2008). Therefore, a precise estimation of $\alpha$ is a central parameter required in the quest to understand the global warming tendency.

ECS is derived by taking advantage of $N=0$, which is apparent from its definition. Therefore, if $\alpha$ is already known, ECS can be expressed as

$$
E C S=\frac{F_{2 \times}}{\alpha}=s F_{2 \times},
$$

where $F_{2 \times}$ is the radiative forcing due to a doubling of the $\mathrm{CO}_{2}$ concentration, and $s$ is the effective climate sensitivity parameter $\left[\mathrm{K} / \mathrm{W} / \mathrm{m}^{2}\right]$. As the climate feedback parameter $\alpha$ increases, negative feedback increases, and the system becomes more stable.

In this respect, uncertainty in estimating the value of $\alpha$ is primarily due to the framework of climate models, such as the implemented calculation schemes for clouds. In addition, ECS cannot be directly estimated when using the climate system in historical experiments or in the ScenarioMIP experiment, as these are not considered to be in equilibrium states. In practice, $\alpha$ is estimated from climate fluctuations, and it is thus dependent on the climate state of the period in focus (Gregory et al. 2002; Gregory et al. 2004; Forster and Gregory 2006; Tett et al. 2006; Otto et al. 2013). As $\alpha$ cannot be obtained as a constant value, it is referred to as effective climate sensitivity 
dependency of $\alpha$ has recently attracted attention as an important source of uncertainty in projecting the warming rate of future climates. Furthermore, when using certain climate models, ensembles of historical simulations result in large uncertainties when estimating $\alpha$ (Watanabe et al. 2021), which indicates the possibility that internal variability also plays an important role in climate feedback variation.

Recently, Gregory and Andrews (2016) examined the time changes of $\alpha$ by introducing the feedback parameter variation. They achieved this by applying the parameter defined in Gregory et al. (2004), which is as follows,

$$
\tilde{\alpha}=-\frac{d N}{d T},
$$

83

where $\tilde{\alpha}$ is known as the differential feedback parameter (DFP), and its value is defined by the slope of the ordinary least squares (OLS) regression of the annual means of $N$ against $T$ over 30 years. They also estimated the DFP value in atmospheric general circulation model simulations (AGCM, Had GEM2, and HadCM3 in their study) using observed SST and sea ice with preindustrial forcing ( $F=0$, which is referred to as the amipPIForcing experiment). The DFP from the model ensembles was an average of $1.7 \mathrm{~W} / \mathrm{m}^{2} / \mathrm{K}$, and the results also provided interdecadal variations. The study revealed that the main control of DFP variations was changes in the SST trend pattern. The results of another study using other CMIP5 models also showed similar interdecadal DFP variability (Andrews et al. 2018).

The observed SST trend pattern change in Gregory and Andrews (2016) is composed of externally forced variability and internal variability on annual to interdecadal timescales. However, further investigations of the internal variability of DFP and deriving an accurate evaluation of this would enable verification of the role of internal variability in climate feedback variation and its physical mechanism in atmosphere-ocean coupling systems. In addition, refining climate feedback estimations would improve near-future climate predictions, in which both trends of internal variability and global warming play important roles. Therefore, this study defines a new feedback parameter to determine the influence of internal variability in relation to variations in DFP, and then clarifies its mechanism.

The aims of this study are as follows: to demonstrate the interdecadal variability of climate feedback by proposing a new feedback parameter, known as the Perturbational Feedback Parameter (PFP); to identify changes in the background field that are closely connected to variations in the parameter; and to clarify the mechanism involved in feedback variability, with a particular focus on the contributions from annual and interannual variations that dominate under the background states.

The remainder of this paper is organized as follows. Section 2 describes the materials and methods used, with a particular emphasis on defining the PFP. The properties of the PFP and the features in the background field that are deeply connected to PFP variations are provided in Section 3. The changes in annual and interannual

108 variations in relation to the background changes and their contribution to PFP variations are also clarified. Section 4 discusses the results and presents the main conclusions. 
111 2. Materials and methods

$112 \quad 2.1 \quad$ Data

113 We analyzed the simulation results from the $6^{\text {th }}$ version of the Model for Interdisciplinary Research on

114 Climate (MIROC6), which contributed to CMIP6 (Tatebe et al. 2019). The "piControl simulation," simulates

115 atmospheric and oceanic interdecadal variation over 800 years (3200-3999, virtual years from the simulation

116 start) by keeping the atmospheric forcing components constant in the preindustrial state, and the following data

117 were obtained from the simulation: surface temperature(ts), downward shortwave radiation flux at TOA (rsdt,

118 TOA: top of atmosphere), upward shortwave radiation flux at TOA (rsut), upward longwave radiation flux at

119 TOA (rlut), clear-sky upward shortwave radiation flux at TOA (rsutcs), clear-sky upward longwave radiation

120 flux at TOA (rlutcs), mass fraction of cloud water (clw), mass fraction of cloud ice (cli), zonal wind (ua),

121 meridional wind (va), vertical wind (wap), atmospheric temperature (ta), and seawater temperature (thetao). The

122 horizontal resolution of the model data was $1.4^{\circ} \times 1.4^{\circ}$ (for seawater temperature, $0.5-1^{\circ} \times 1^{\circ}$ ), and the vertical

123 resolution was as follows: 19 layers (from $1000 \mathrm{hPa}$ to $1 \mathrm{hPa}$ ) for ua, va, and wap; 81 layers for clw, cli, and ta

124 (surface to $0.004 \mathrm{hPa}$ by using a hybrid $\sigma-p$ coordinate; Arakawa and Konor (1996) for the purpose of

125 reproducing stratospheric circulation); and 62 layers (sea surface to the sea bottom by using a hybrid $\sigma-z$

126 coordinate) for thetao (49 layers for tropics). The annual mean data derived from monthly mean data were

127 analyzed in this study.

128

2.2 Definition of PFP (Perturbational Feedback Parameter)

130 In this section, we define the perturbational feedback parameter (PFP), $\alpha$, with the aim of enabling an

131 investigation of the interdecadal variations in the strength of climate feedback associated with internally

132 generated climate variability.

133 The values of the PFP are defined as the linear regression coefficient obtained from the relation between

134 the global-mean anomalies of the net downward radiation flux at the top of the atmosphere, $N^{\prime}$, and those of

135 surface temperature, $T^{\prime}$, within a 30-year window (Gregory and Andrews 2016),

136

$$
\alpha=-\frac{\Delta N^{\prime}}{\Delta T^{\prime}}
$$

It is of note that the anomalies deviate from the climatology of 800-year-long simulations and that the

140 PFP is derived by inverting the sign as in Gregory and Andrews (2016). From this definition, the PFP indicates

141 how the global mean net downward radiation flux changes according to a rise in the global mean surface

142 temperature, and negative feedback increases when the PFP is larger.

143 The temporal evolution of the PFP value is first defined, and the physical mechanism controlling PFP

144 variations is then clarified by focusing on changes in the interannual fluctuations and mean states within 30-year 145 windows. 
In this section, we define a modified regression value in detecting predominant fluctuations that characterize PFP variations, used in 3.3. In calculating the regression values with the area-averaged SST fluctuations (i.e., Nino3.4 SST or the northeastern Pacific SST shown in Figures 3c), we introduced a scaling factor, which is defined as the regression of area-averaged SST with global-mean surface temperature fluctuations. In other words, we examined the product of a specific fluctuation at each grid point regressed onto the area-averaged SST and the area-averaged SST regressed onto the global-mean surface temperature. These scaled regression values enabled us to estimate the contribution to the global-mean fluctuation at each grid point through a specific climate mode represented by the fluctuation in area-averaged SST, and the following equations were employed,

Modified Regression value $=$

$$
\frac{\sum\left(V_{\text {local }}-\bar{V}_{\text {local }}\right)\left(T_{\text {Nino3.4 }}-\bar{T}_{\text {Nino3.4 }}\right)}{\sum\left(T_{\text {Nino3.4 }}-\bar{T}_{\text {Nino3.4 }}\right)^{2}} \times \frac{\sum\left(T_{\text {Nino3.4 }}-\bar{T}_{\text {Nino3.4 }}\right)\left(T_{\text {global }}-\bar{T}_{\text {global }}\right)}{\sum\left(T_{\text {global }}-\bar{T}_{\text {global }}\right)^{2}},
$$

Modified Regression value $=$ is Nino3.4 SST, $T_{N E P}$ is northeastern Pacific SST, and the superscript bar shows the average data for either 424 years in PFP_large or 365 years in PFP_small.

166

\section{Results}

$168 \quad 3.1 \quad$ PFP variations and associated properties

Although external forcing was fixed in the 800-year-long simulation, values of PFP showed interdecadal variations (Figure 1), and the average and standard deviation of its timeseries were $1.47\left[\mathrm{~W} / \mathrm{m}^{2} / \mathrm{K}\right]$ and $0.37\left[\mathrm{~W} / \mathrm{m}^{2}\right]$, respectively.

Interdecadal variations in PFP were accompanied by large-scale climate variability within the 30-year

173 running mean states (Figure 2). Figure 2a shows a correlation map between the 30-year running mean surface

174 temperature and PFP variations. When the PFP was positive, the surface temperature increased over the

175 equatorial Pacific and decreased over the western equatorial Pacific, and an east-west contrast was clearly

176 evident. Consequently, the zonal SST contrast along the equator was weakened. Figure $2 \mathrm{~b}$ shows the longitude-

177 depth section of the 30-year running mean ocean-water temperature averaged over $5 \mathrm{~S}-5 \mathrm{~N}$ regressed onto the

178 PFP. Corresponding to the SST changes, the subsurface ocean temperature weakened the zonal gradient of the ocean thermocline over the equatorial Pacific. 
182 3.2.1 Fluctuations of surface temperature and net downward radiation flux within a 30-year window

183 Variations in both the surface temperature and net downward radiation flux were found to contribute to

184 PFP variation. We thus investigated the correlations between PFP variation and the standard deviations of global 185 mean surface temperature and net downward radiation flux within a 30-year window to determine which variable 186 provided the most dominant contribution. The results showed that the correlation between PFP and the standard 187 deviation of the global mean surface temperature was 0.52 , whereas that of the net downward radiation flux was 1880.76 (Figure 3a, b). This showed that the variation in PFP was mainly controlled by the variation width of the 189 global mean net downward radiation flux and not by surface temperature within a 30-year window.

190 It was then necessary to determine the area in which the global mean net downward radiation flux change 191 originated. Using the PFP time series, the regression maps of the standard deviations of local surface temperature 192 and net downward radiation flux were analyzed to provide insight into gaining an understanding of the physical 193 mechanism. Figure $3 \mathrm{c}$ shows a map of the standard deviation of surface temperature regressed onto the PFP, where 194 it is evident that deviations in the annual mean surface temperature over the equatorial Pacific increase when the 195 PFP is large. In addition, large signals are also found over the mid-latitudes of the northern Pacific and Alaska.

196 Figure 3d shows a map of the standard deviation of net downward radiation flux regressed onto the PFP, 197 where it is evident that deviations of annual net downward radiation flux over the equator and its north-south area 198 increase when the PFP is large. The PFP value is directly controlled by deviations in the global mean net downward 199 radiation flux over 30 years (Figure 3b), and it is mainly controlled by the equatorial and subtropical net downward 200 radiation flux amplitude in the Pacific (Figure 3d). However, PFP variation is less dependent on the global mean 201 surface temperature amplitude (Figure 3a), while it is related to the local surface temperature in the equatorial and 202 northeastern Pacific (Figure 3c). This suggests that changes in the surface temperature over the equatorial and 203 northeastern Pacific may drive net downward radiation flux changes over the tropical and subtropical Pacific via atmospheric circulation and cloud changes. 3.2.2 Differences between the interannual variations of PFP_large and PFP_small

To clarify the physical mechanisms that control the statistical relationships between PFP and surface temperature and net downward radiation flux, we conducted composite analyses based on the PFP values. The

209 PFP values that fluctuated in 30-year windows by over one standard deviation (in either positive or negative values)

210 were categorized as PFP_large and PFP_small, respectively, and the differences between these two categories

211 were discussed. In particular, we examined the sensitivity of surface temperature and net downward radiation flux

212 variations at each grid point to the variations in global-mean surface temperature, as its amplitude was less 213 dependent on the PFP values (Figure 3a).

214 PFP_large was thus defined as a PFP value larger than $1.85\left[\mathrm{~W} / \mathrm{m}^{2} / \mathrm{K}\right]$, which was the average PFP variation 215 plus one standard deviation of variation in 800 years, and PFP_small was defined as a PFP value less than $2161.11\left[\mathrm{~W} / \mathrm{m}^{2} / \mathrm{K}\right]$, which was the average PFP variation minus one standard deviation of variation in 800 years. A 217 total of 424 years and 365 years fell into each respective category. It is of note that although specific years in a 30 - 
year window of PFP_large could be concurrently counted in another 30-year window of PFP_small, this did not

219 disrupt our analysis because we used the results to analyze the statistical features of 30-year windows. The 220 regression difference from PFP_large to PFP_small was then analyzed.

Figure 4a shows a map of the differences between PFP_large and PFP_small when the local surface temperature was regressed onto the global mean surface temperature anomaly. The result reveals an anomalous warming of surface temperature in the eastern equatorial Pacific and an anomalous cooling in the extratropical

224 Pacific with a rise in the global mean surface temperature rise in PFP_large. Again, the positive values in the 225 tropical Pacific correspond to the intensification of the ENSO amplitude when the PFP value increases, as mentioned in Section 4.1. Figure 4b shows a map of the difference between PFP_large and PFP_small when the net downward radiative flux was regressed onto the global mean surface temperature. The result reveals an anomalous net downward radiation flux in the northern part of the equator and an anomalous net upward radiation flux in the subtropics and on the equator.

However, the signals in the net downward radiation flux in Figure 4a do not merely represent local responses to the surface temperature fluctuations. Large regression differences are also found in the tropical Pacific, which implies that significant changes occur in the Pacific ITCZ and the subtropical Pacific rather than in the midand high latitudes. We thus focus on the tropical and subtropical Pacific areas to conduct the following analyses.

The difference in the regression value of net downward radiative flux in Figure $4 \mathrm{~b}$ correlates well with that of the cloud distribution. Figure $5 \mathrm{a}$ and $5 \mathrm{~b}$ are maps of the differences between the cloud water contents of PFP_large and PFP_small in the low and middle troposphere, respectively, regressed onto the PFP, which were derived using the same method as that used to obtain the results shown in Figure 4a and 4b. Low-level clouds showed anomalous positive values in the subtropical Pacific Ocean (Figure 5a). Figure 5b shows that middle-level clouds have anomalous negative values in the northern part of the tropical Pacific and positive values along the equatorial Pacific, and these changes in clouds may be comparable to those of the net downward radiative flux (Figure 4b).

Figure 6 shows the meridional circulation of the atmosphere, air temperature, and the mass content of cloud water that were zonally averaged in the eastern tropical and subtropical Pacific (shown in Figure 4a, 30S-30N)

244 where the regression values relate to large differences in surface temperature (Figure 4a). There is an ascending 245 flow anomaly (positive value of the regression difference) on the equator and a descending flow anomaly (negative 246 value of the regression difference) in the subtropics, and this enhances the Hadley circulation when the PFP value 247 is large (Figure 6a).

248 Consistent with the enhanced convective activity along the equator, there is a warming anomaly (positive regression value difference) in the middle to upper layers and the lower layers on the equator (Figure 6b). The

250 cloud water content increases and decreases, particularly in the middle layer over the equatorial and off-equatorial 251 areas, respectively (Figure 6c), which suggests that the convective activity is concentrated in a narrow area along 252 the equator. In addition, there is a cooling anomaly (negative value of regression difference) in the lower layers of 253 the subtropics (Figure 6b), where descending flow prevails (Figure 6a) and cloud water content above the layers 254 increases (Figure 6c). 
It has been revealed that the strengthening of ascending flow on the equator due to surface temperature rise in the eastern Pacific and the descending flow in the subtropics due to the enhanced static stability causes changes in the amount and distribution of cloud, and thus changes in net downward radiation change. Although these variations are superposed by multiple timescale fluctuations, it is uncertain which timescale fluctuations are dominant in characterizing the aforementioned variations.

The Nino3.4 index (SST anomaly averaged over 5S-5N, $170 \mathrm{~W}-120 \mathrm{~W}$, blue rectangle in Figure 3c) and the northeastern Pacific surface temperature (SST anomaly averaged over 30N-45N, $170 \mathrm{~W}-135 \mathrm{~W}$, red rectangle in Figure 3c) have large signals in Figure 3c, and they were selected to show the extents to which SST or atmospheric variation, which are connected to SST variation in the designated areas, can explain the changes in cloud and net downward radiation flux.

To capture the dominant variations, spectrum analyses were conducted using normalized Nino3.4 SST and northeastern Pacific SST, and Figure 7 shows the spectrum of SST when using both. Nino3.4 SST has a spectrum peak at around five years, whereas the northeastern Pacific SST has a spectrum peak at 10 to 20 years. The former corresponds to the ENSO period, and the latter corresponds to interdecadal variation in the mid-latitudes of the Pacific, such as the PDO (Mantua et al. 1997). These results show that Nino3.4 SST and the northeastern Pacific SST represent different variations over certain time scales, and the influence of both elements can be examined through these indices.

In calculating the regression values with the area-averaged SST fluctuations (i.e., Nino3.4 SST or the northeastern Pacific SST), we used the modified regression values defined in 2.3. Through this manipulation, it was possible to determine how much of each physical quantity relating to variations in the Nino3.4 index, equatorial Pacific SST, or northeastern Pacific SST (representing midlatitude variation), corresponded to the variations in global mean surface temperature.

The patterns shown in both maps (Figure 8c, f) of the differences in the modified regression value of the net downward radiation flux defined in the above equations (Eq (2-2) and $\mathrm{Eq}(2-3)$ ) resemble those of the differences in the regression values against global mean surface temperature (Figure $4 \mathrm{~b}$ ).

The areas showing large signals in the subtropics in the map of net downward radiation flux against global mean surface temperature (Figure $4 \mathrm{~b})$ occur both in the northern Pacific (15N-32N, 170E-120W) and in the southern Pacific (15S-30S, 160E-130W). Therefore, we calculated the regression value difference averaged over those areas (blue and purple rectangles shown in Figure 8c, f). The modified regression value differences over those areas were -1.73 and $-2.14\left[\mathrm{~W} / \mathrm{m}^{2}\right]$ for the Nino3.4 index and -1.71 and $-0.54\left[\mathrm{~W} / \mathrm{m}^{2}\right]$ for the northeastern Pacific SST, respectively. However, the regression value differences against the global mean surface temperature over those areas were -4.05 and $-2.97\left[\mathrm{~W} / \mathrm{m}^{2}\right]$. Therefore, the modified regression value differences were approximately $42.7 \%$ and $72.1 \%$ for Nino3.4 SST and $42.3 \%$ and $18.1 \%$ for northeastern Pacific SST compared to the global mean surface temperature.

In the same manner, the regression differences of surface temperature, sea level pressure (SLP), and the mass content of cloud water were examined, with a focus on the connection between the net downward radiation 
flux in the northern Pacific and Nino3.4 and northeastern Pacific SST variation. Figure 8a and 8d are maps of the 293 modified regression value differences of surface temperature and sea level pressure against Nino3.4 SST and the

294 Northeastern Pacific SST, respectively. The shape of the regression difference in surface temperature is long, 295 slender, and positive on the equatorial Pacific against Nino3.4 SST, whereas there is a wider positive regression 296 difference against the northeastern Pacific SST. Furthermore, their distributions in the northern Pacific are 297 completely different, which affirms that Nino3.4 SST and the northeastern Pacific SST represent different 298 variations both spatially and temporally.

299 With respect to SLP, the negative regression difference against northeastern Pacific SST in the northern 300 Pacific, which represents the strength and position of the Aleutian low, is located more closely to Alaska than 301 when using the Nino3.4 SST (Figure 8a, d). In addition, the positive regression difference against the northeastern

302 Pacific SST in the northwestern Pacific, which denotes anticyclonic circulation, extends more over the middle of 303 the Pacific compared to when using Nino3.4 SST. This SLP pattern strengthens the northern wind inflow, which 304 is supposed to lower the northeastern Pacific SST.

$305 \quad$ Figure $8 \mathrm{~b}$ and $8 \mathrm{e}$ are maps showing the modified regression value differences of the mass cloud water 306 content against Nino3.4 SST and Northeastern Pacific SST, respectively. With respect to the cloud water content, 307 the regression value difference against northeastern Pacific SST is more positive in the northern subtropical Pacific 308 than when against Nino3.4 SST. This result can be attributed to the strengthening of the northern wind inflow, 309 which provides a more statically stable environment that is appropriate for increasing low cloud.

\section{4. Summary and Discussion}

312 This study used the PFP, a new feedback parameter, to investigate the changes in climate feedback due to 313 internal variations. Data from the MIROC6 piControl simulation, which is one of the main models in CMIP6, were 314 analyzed. The PFP was found to vary on interdecadal time scales, and its amplitude was comparable to that of the 315 DFP calculated in previous studies (Andrews et al. 2018) using the AGCM with observed SST as a boundary 316 condition. The results show that climate feedback intensity can be modulated greatly by internal variations.

317 Variations in PFP were found to be connected to the background field, and a positive surface temperature 318 anomaly in the eastern Pacific and a negative anomaly in the western Pacific were determined, which resulted in 319 a less tilted thermocline. This anomalous SST contrast in the equatorial Pacific agrees with the results of 320 Watanabe et al. (2021). As they focused on the SST trend pattern, the results indicate that recent SST trend 321 patterns in the equatorial Pacific, such as the hiatus, can be explained by internal variability. We also found that 322 annual changes in the globally averaged net downward radiation flux, which occurred in accordance with 323 background change, caused variations in the PFP.

324 To investigate the cause of changes in the global mean net downward radiation flux, regression analyses 325 were conducted against global mean surface temperature using the difference between PFP_large (PFP $>1.85$ $326 \mathrm{~W} / \mathrm{m}^{2}$, expressed as PFP_large) and PFP_small (PFP $<1.11 \mathrm{~W} / \mathrm{m}^{2}$, expressed as PFP_small). As the global mean 327 surface temperature rose, the surface temperature rise in the equatorial Pacific increased in PFP_large, owing to 328 enhancement of the ENSO amplitude. This pattern corresponds with that of ENSO determined in several studies, 
which show that its amplitude increases when the east-west SST contrast as a background field is reduced 330 (Guilyardi et al. 2009; Kim et al. 2014; Cai et al. 2015). In addition, changes in the net downward radiation flux 331 values became increasingly positive in the northern part of the equator and increasingly negative in the equator 332 and subtropics in PFP_large. These distribution changes in the net downward radiation flux were found to 333 correspond well to those of clouds, when there was a low cloud increase in the subtropics and middle to high cloud 334 changes around the equator, which revealed that changes in the net downward radiation flux in these areas were 335 attributed to the amount and distribution of cloud. The low cloud increase in the subtropics (Figure 5a, 6c), where 336 descending flow prevails permanently (Figure 6a), is considered to be caused by an intensification of descending 337 flow and a possible decline in dry air entrainment due to the higher static stability (Bretherton 2015). The low 338 cloud increase (Figure 5a, 6c) is consistent with the results of a preceding study (Zhou et al. 2016) that focused on 339 the increasing trends in low cloud cover in the eastern Pacific in correspondence with SST trend patterns, rather 340 than increasing anomalies in the subtropics.

341 These variational characteristics were derived as a superposition of multiple time- and special-scale 342 fluctuations. To evaluate the fluctuations that were dominant in controlling PFP variations, a modified regression 343 value was defined against Nino3.4 SST (SST anomaly averaged over 5S-5N, $170 \mathrm{~W}-120 \mathrm{~W}$, blue rectangle in 344 Figure 3c, which has a spectrum peak in near 5 years as shown in Figure 7) and Northeastern Pacific SST (SST 345 anomaly averaged over 30N-45N, $170 \mathrm{~W}-135 \mathrm{~W}$, red rectangle in Figure 3c, which has a spectrum peak in the later 34610 years in Fig 7). This revealed that the low cloud increase and consequent changes in net downward radiation 347 flux in the southern Pacific were mainly attributed to changes in ENSO, as represented by the modified regression 348 value against Nino3.4 SST, whereas that in the northern Pacific was contributed to both by changes in ENSO and 349 longer changes in fluctuations (such as the PDO) in the northern mid-latitudes, which strengthened the static 350 stability of the subtropics. Since northeastern Pacific SST is located at higher latitudes than the subtropics, it is 351 anticipated that the increase in cloud water in the northern subtropics is not brought directly by the northeastern 352 Pacific SST, but through atmospheric circulation change over longer time scales, which can also control the 353 northeastern Pacific SST.

It has been suggested that variations in DFP are affected by lower cloud increases in the eastern Pacific in 356 relation to changes in SST trend patterns, active convection in the western Pacific, and the enhancement of static 357 stability in the boundary layer due to atmospheric heating in the middle-upper layer (Gregory and Andrews 358 2016; Zhou et al. 2016). The results of this study also indicate that increases in lower clouds and the subsequent 359 increase in reflection have a great impact on the radiation budget at the top of the atmosphere; however, this 360 occurs in the subtropical Pacific and is caused by multiple internal fluctuation changes.

361 The study of Shiogama et al. (2012) also showed that cloud negative feedback due to ENSO was intensified 362 when using a perturbed physics ensemble in MIROC5, and that of Toniazzo et al. (2008) achieved similar results 363 with the GCM of the Hadley Centre. Differences in the background features may thus influence the detailed 364 mechanisms working as negative feedback, and in this study we indicated that the zonal SST contrast along the 365 equator in the background was reduced due to global warming. 
Fluctuations in the northeastern Pacific, defined by the northeastern Pacific SST in this study, involve decadal to interdecadal variations, such as that of the PDO. A change in the strength of the Aleutian low is known to be one of the drivers of this change (Newman et al. 2016). From this, variation changes or extreme position shifts of sea level pressure in the northern Pacific can be caused by teleconnection pattern changes, such as the NPO (Wallace and Gutzler 1981), which is from the equatorial Pacific (to the northern Pacific), and the PJ pattern (Nitta 1987), which is from the maritime continent, and thus decadal fluctuations occur in the northern Pacific. However, for teleconnection pattern changes, the influence of the background fields of the atmosphere cannot be neglected.

Teleconnection differences and their mechanisms associated with background changes are currently being studied. Michel et al. (2020) showed that many studies have suggested that the maximum region of SLP variation has shifted toward the northeast (Christensen et al., 2007; Muller and Roeckner, 2008; Christensen and Coautors, 2013). Other studies have provided contrasting results and suggested that the SLP anomaly has become larger without changing its position (Scheneider et al. 2009), has become weaker (Herceg et al. 2007), or has shifted towards a westward direction (Zhou et al. 2014). One of reasons for such inconsistencies is the lack of a coherent modeling span or ensemble size used in the different studies, and this has caused non-negligible differences in the background field due to phase disagreements associated with internal variation (Michel et al., 2020).

Thus, elucidating air-sea interactions between the tropics and the extra tropics through large ensemble simulations and multi-model analyses will contribute to improving the evaluation of climate feedback.

\section{Abbreviations}

CS, climate sensitivity; ECS, equilibrium climate sensitivity; GCM, general circulation model; AR1: $1^{\text {st }}$ assessment report; AR5: $5^{\text {th }}$ assessment report; EffCS, effective climate sensitivity; DFP, differential feedback parameter; AGCM, atmospheric general circulation model; SST, sea surface temperature

\section{Declarations}

\section{Acknowledgements}

The MIROC6 dataset supporting the conclusions of this article is available from https://esgfnode.llnl.gov/search/cmip6/.

This work was supported by JSPS KAKENHI Grant Number JP19H05703 and by the Integrated Research Program for Advancing Climate Models (Tougou) Grant Numbers JPMXD0717935457 and JPMXD0717935715.

\section{Author contributions}

399 Ko Tsuchida: Conceptualization; data analysis and investigation; writing (and original draft).

400 Takashi Mochizuki: Funding acquisition, resources, supervision, writing, review, and editing.

401 Ryuichi Kawamura and Tetsuya Kawano: Discussion and advice. 
Andrews T, Gregory JM, Mark et al. (2012) Forcing, feedbacks and climate sensitivity in CMIP5 coupled atmosphere-ocean climate models. Geophys Res Lett 39:L09712. doi:10.1029/2012GL051607

Andrews T, Gregory JM, Paynter DSilvers, L. G., Zhou, C., Mauritsen, T., et al. (2018): Accounting for changing

Arakawa, A. and Konor, C. S. (1996): Vertical differencing of the primitive equations based on the CharneyPhillips grid in hybrid $\sigma-\mathrm{p}$ vertical coordinates, Mon. Weather Rev., 124, 511-528.

414 Bony S, Colman R, Kattsov VM et al. (2006) "How well do we understand and evaluate climate change feedback processes?" J Clim 19:3445-3482

416

417 Bretherton CS. (2015): Insights into low-latitude cloud feedbacks from high resolution models. Phil. Trans. R.

418 Soc. A 373: 20140415. http://dx.doi.org/10.1098/rsta.2014.0415

419

420 Cai, W., Santoso, A., Wang, G. et al. (2015): ENSO and greenhouse warming. Nature Clim Change 5, 849-859.

421 https://doi.org/10.1038/nclimate2743

422

423 Christensen and Coauthors (2013): Climate phenomena and their relevance for future regional climate change.

424 Climate Change (2013): The Physical Science Basis, T. F. Stocker et al., Eds., Cambridge University Press, $425 \quad 1217-1308$.

427 Forster PMF, Gregory JM (2006) The climate sensitivity and its components diagnosed from earth radiation budget 428 data. J Clim 19:39-52. DOI: https://doi.org/10.1175/JCLI3611.1

430 Gregory J, Webb M (2008) Tropospheric adjustment induces a cloud component in CO2 forcing. J Clim 21:58$431 \quad 71$

433 Gregory JM, Andrews T (2016) Variation in climate sensitivity and feedback parameters during the historical period. Geophys Res Lett 43:3911-3920. doi:10.1002/2016GL068406

436 Gregory JM, Andrews T, Ceppi P et al. (2020) How accurately can the climate sensitivity to CO2 be estimated 437 from historical climate change? Clim Dyn 54:129-157. https://oi.org/10.1007/s00382-019-04991-y

439 Gregory JM, Ingram WJ, Palmer MA, Jones GS et al. (2004) A new method for diagnosing radiative forcing and 
442 Gregory JM, Stouffer RJ, Raper SCB et al. (2002) An observationally based estimate of the climate sensitivity. J

443 Climate 15:3117-3121

445 Guilyardi, E., Wittenberg, A., Fedorov, A., Collins, M., Wang, C., Capotondi, A., et al. (2009): Understanding El

446 Niño in ocean-atmosphere general circulation models: Progress and Challenges Bull. Amer. Meteor. Soc., 90,

447 325-340. https://doi.org/10.1175/2010JCLI3679.1.

448

449 Herceg Bulic', I., and_C. Branković (2007): ENSO forcing of the Northern Hemisphere climate in a large

450 ensemble of model simulations based on a very long SST record. Climate Dyn., 28, 231-254, https://doi.org

$451 / 10.1007 / \mathrm{s} 00382-006-0181-1$.

452

453 Kim et al. (2014): Response of El Nino sea surface temperature variability to greenhouse warming. Nature Clim.

454 Change 4, 786-790.

455

456 Knutti R, Hegerl GC (2008) The equilibrium sensitivity of the Earth's temperature to radiation changes. Nat Geosci

457 1:735-743. https://doi.org/10.1038/ngeo337

458

459 Mantua et al. (1997) : A Pacific Interdecadal Climate Oscillation with Impacts on Salmon Production; Bull.

460 Amer. Meteor. Soc., Vol.78, pp.1069-1079.

461

462 Meehl and Teng (2007): Multi-model changes in El Niño teleconnections over North America in a future warmer climate. Clim Dyn 29, 779-790. https://doi.org/10.1007/s00382-007-0268-3.

465 Michel, C., C. Li, I. R. Simpson, et al. (2020): The Change in the ENSO Teleconnection under a Low Global

466 Warming Scenario and

467 the Uncertainty due to Internal Variability. J. Clim, 33, 4871-4889,

468 https://doi.org/10.1175/JCLI-D-19-0730.1.

469

470 Müller and Roeckner (2008): ENSO teleconnections in projections of future climate in ECHAM5/MPI-OM.Clim Dyn 31, 533-549. https://doi.org/10.1007/s00382-007-0357-3.

472

473 Newman et al. (2016): The Pacific Decadal Oscillation, revisited. J. Clim. 29, 4399-4427.

474

475 Nitta (1987): Convective activities in the tropical western Pacific and their impact on the northern hemisphere 476 summer circulation. J. Meteor. Soc. Japan, 78. 141-157. 
478 Otto A, Otto FEL, Boucher O et al. (2013) Energy budget constraints on climate response. Nat Geosci 6:415-416.

479 https://doi.org/10.1038/ngeo 1836

480

481

Power et al. (1999) : Inter-decadal modulation of the impact of ENSO on Australia; Clim. Dyn., 15, pp.319-324.

482

483 Schneider et al. (2009): A statistical-dynamical estimate of winter ENSO teleconnections in a future climate. J.

484 Clim, 22, 6624-6638, https://doi.org/10.1175/2009JCLI3147.1.

485

486 Senior CA, Mitchell JFB (2000) The time-dependence of climate sensitivity. Geophys Res Lett 27:2685-2688

487

488 Shiogama, H., Watanabe et al. (2012): Perturbed physics ensemble using the MIROC5 coupled atmosphere-

489 ocean GCM without flux corrections: experimental design and results. Clim Dyn 39, 3041-3056.

490 https://doi.org/10.1007/s00382-012-1441-x

491

492 Tett SFB, Betts R, Crowley TJ et al. (2006) The impact of natural and anthropogenic forcings on climate and

493 hydrology since 1550. Clim Dyn 28:3-34. https://doi.org/10.1007/s00382-006-0165-1

494 https://doi.org/10.1029/2018GL078887

495

496 Tatebe, H., Ogura, T., Nitta, T., Komuro, et al. (2013): Description and basic evaluation of simulated mean state,

497 internal variability, and climate sensitivity in MIROC6, Geosci. Model Dev., 12, 2727-2765,

498 https://doi.org/10.5194/gmd-12-2727-2019.

499

500 Toniazzo and Woolnough (2014): Development of warm SST errors in the southern tropical Atlantic in CMIP5

501 decadal hindcasts. Clim Dyn 43, 2889-2913. https://doi.org/10.1007/s00382-013-1691-2.

502

503 Wallace and Gutzler (1981): Teleconnections in the geopotential height field during the Northern Hemisphere.

504 Mon. Wea. Rev., 109, 784-812, https://doi.org/10.1175/15200493(1981)109,0784:TITGHF.2.0.CO;2.

505

506 Wang et al. (2013) : Northern Hemisphere summer monsoon intensified by mega-El Niño/southern oscillation and

507 Atlantic multidecadal oscillation; Proc Natl Acad Sci USA, Vol.110, No.14, pp.5347-5352.

508

509 Watanabe, M., Dufresne, JL., Kosaka, Y., et al. (2021) Enhanced warming constrained by past trends in

510 equatorial Pacific sea surface temperature gradient. Nat. Clim. Chang. 11, 33-37.

511 https://doi.org/10.1038/s41558-020-00933-3.

512

513 Zhang et al. (1997) : ENSO-like Interdecadal Variability: 1900-93; J. Climate, Vol.10, pp.1004-1020. 
515 Zhou et al. (2014): Global warming induced changes in El Niño teleconnections over the North Pacific and

516 North America. J. Clim, 27, 9050-9064, https://doi.org/10.1175/JCLI-D-14-00254.1.

517

518

519

520

521

522

523

524

525

526

527

528

529

Figure legends

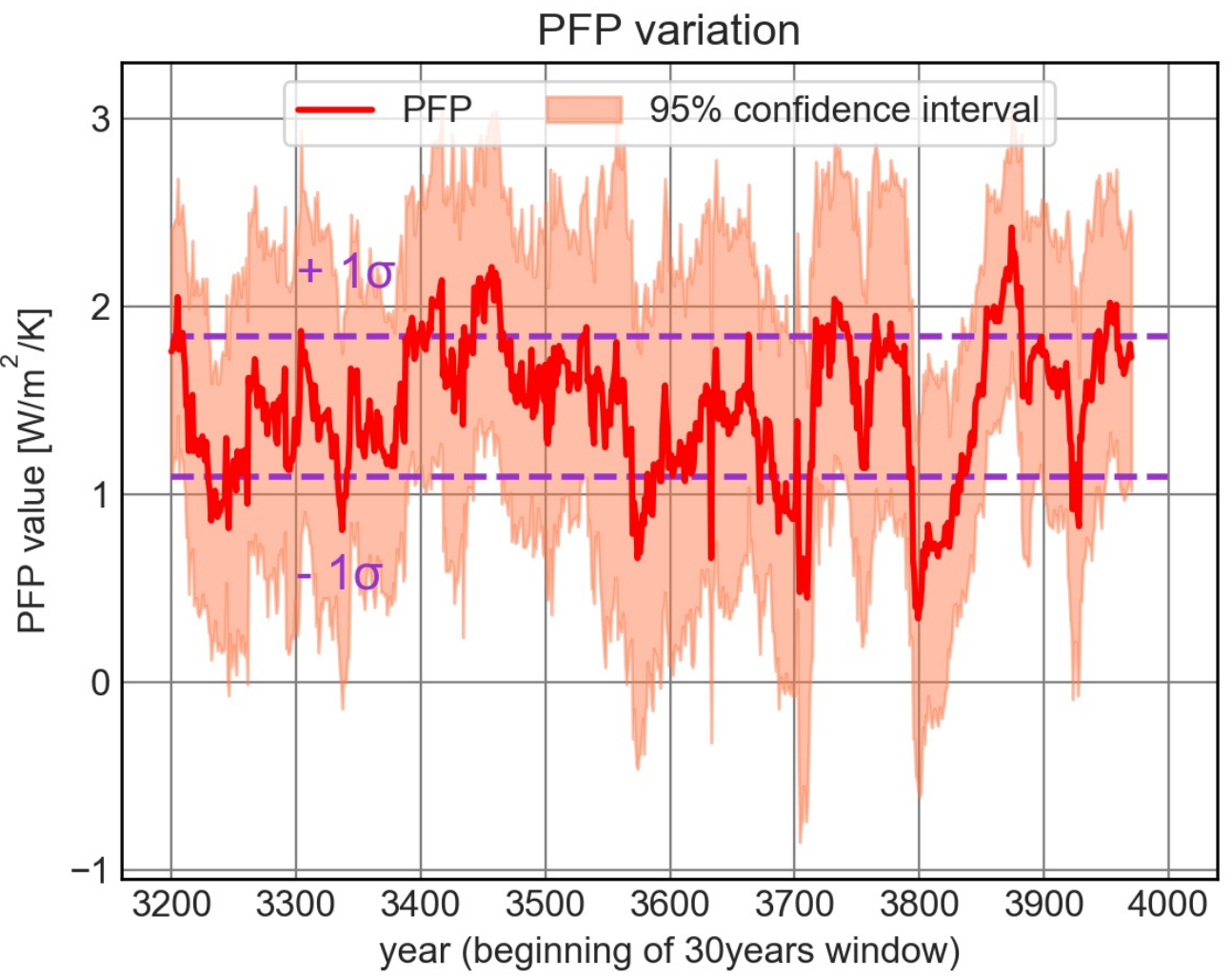

Figure 1. PFP time series (red line) and ranges over the $95 \%$ confidence level (orange shading) derived using the t-test. Purple lines indicate a range of \pm 1 standard deviation from the PFP mean value. 
(a) Cor PFP vs local_T

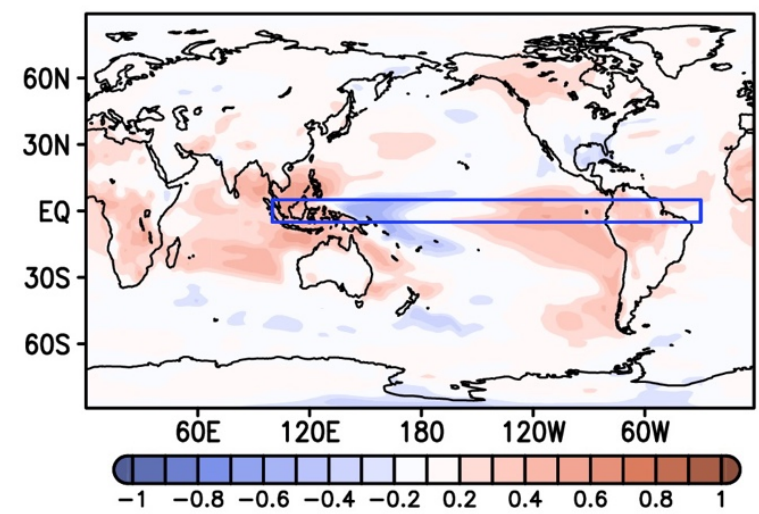

(b) Reg thetao with PFP $\left[\mathrm{K}^{2} / \mathrm{W} / \mathrm{m}^{2}\right]$

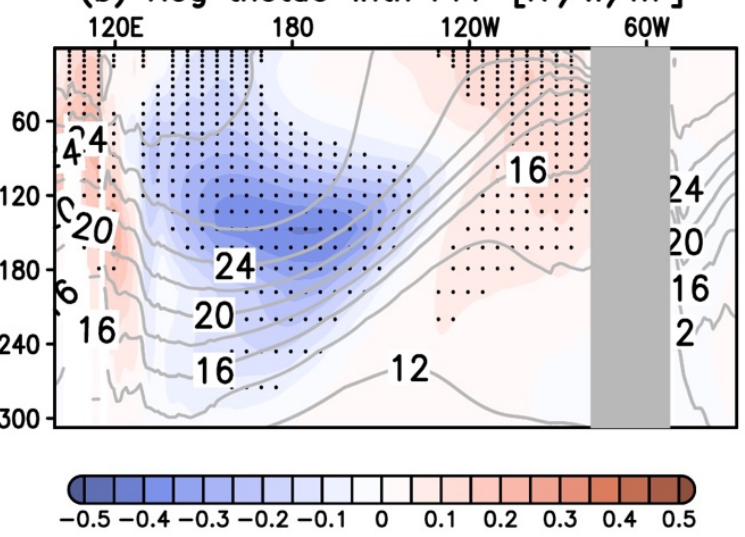

Figure 2.(a) Map showing correlation between 30-year running mean surface temperature and PFP. (b) Longitude-depth section of 30-year running mean ocean-temperature averaged meridionally over the blue rectangle shown in panel (a) regressed onto PFP. Contours in panel (b) show ocean-water temperature averaged over 800 years. Stippling in panel (b) indicates that the regression value is significant at a $95 \%$ confidence level (derived using the t-test technique). 
(a) T stdev vs PFP

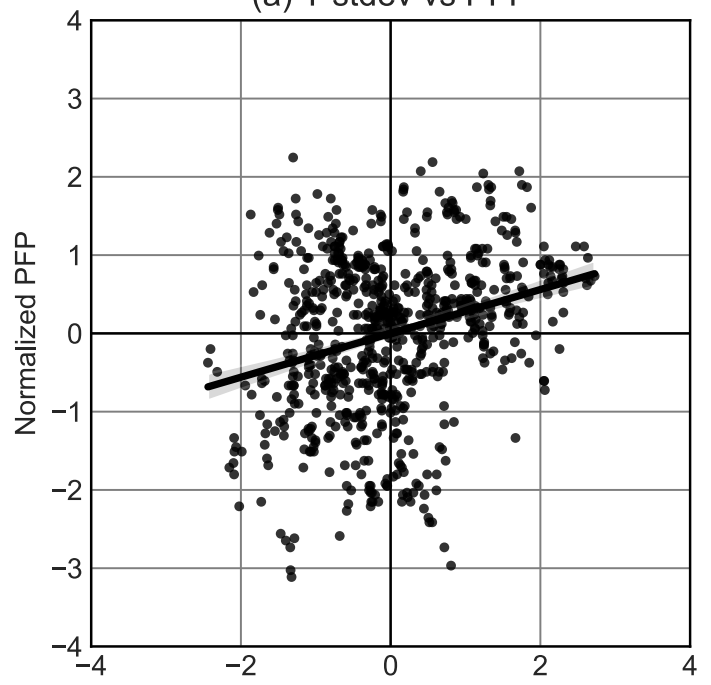

(c) Reg local_T_stdev with PFP $\left[\mathrm{K}^{2} / \mathrm{W} / \mathrm{m}^{2}\right]$ (b) N stdev vs PFP

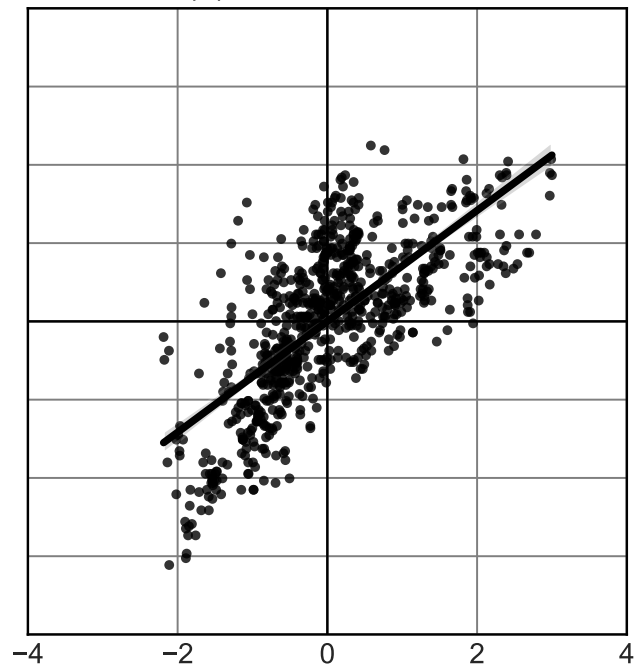

(d) Reg local_N_stdev with PFP [K]
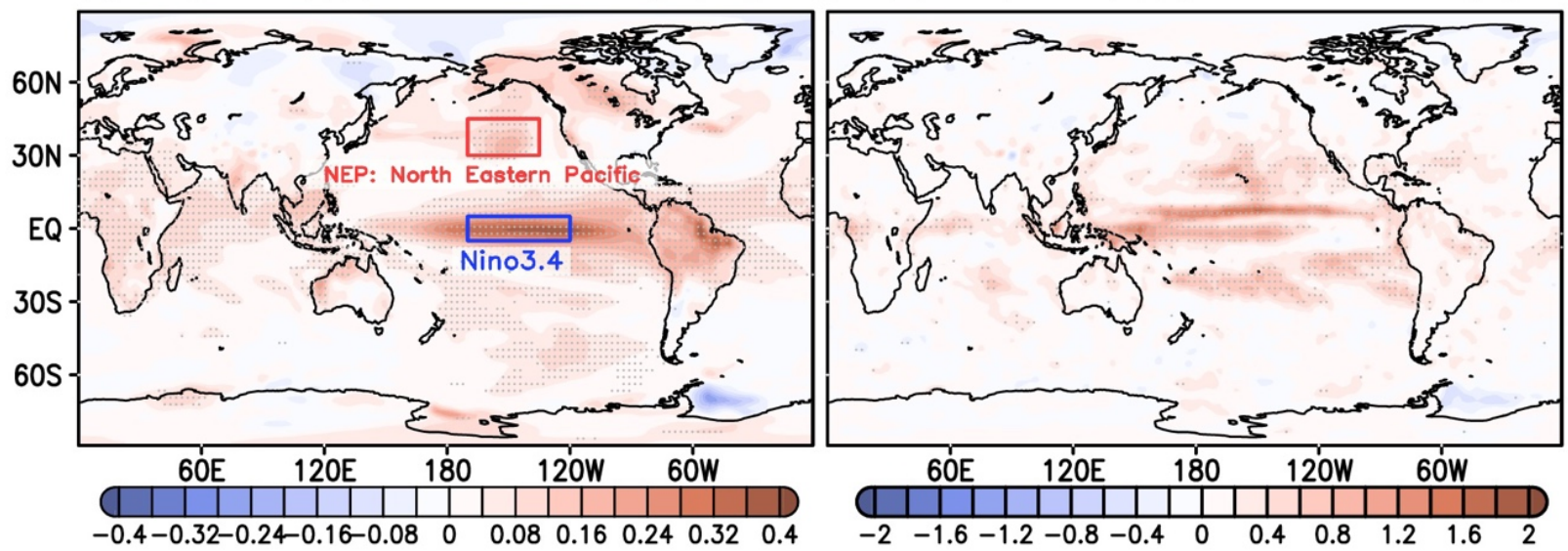

Figure 3. (Upper panels) Scatter plot of normalized PFP against normalized standard deviation of global means of (a) surface temperature and (b) net downward radiation flux at TOA respectively in 30 years. Lines in panels (a) and (b) show the slope of the ordinary least squares (OLS) regression of normalized PFP against the normalized standard deviation of global mean surface temperature and net downward radiation flux at TOA, respectively, in 30 years. (Lower panels) Standard deviations of (c) surface temperature and (d) net downward radiation flux at TOA in 30 years regressed to PFP. Stippling in panels (c) and (d) indicate the areas where the regression value is significant at a $95 \%$ confidence level derived by t-test technique. 
(a) diff. Reg. local_T with glb_T [K/K] (b) diff. Reg. local_N with glb_T [W/m²/K]

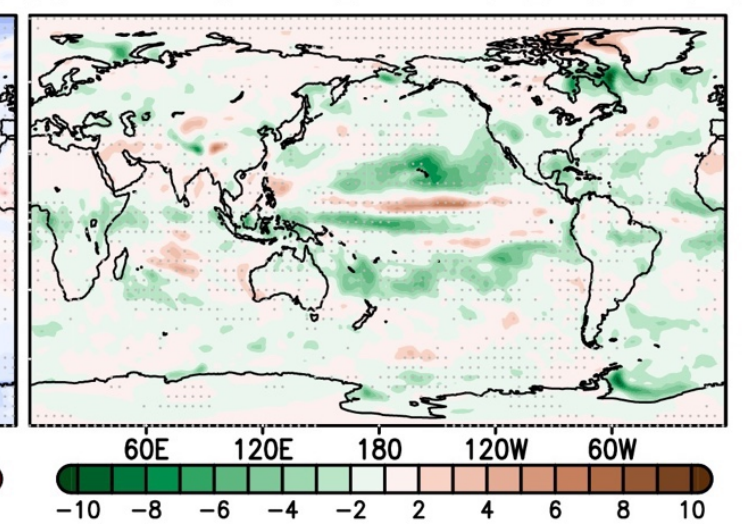

Figure 4. Maps showing differences between PFP_large and PFP_small when (a) surface temperature and (b) net downward radiation flux were regressed onto global mean surface temperature. Stippling indicates the areas where the regression value is significant at a $99 \%$ confidence level (derived using the $t$-test technique). Orange rectangle in panel (a) is the analyzed area in Figure 6.

diff. Reg. local_cloud-water with glb_T [g/kg/K]

(a) lower_layer,sigma-p $=0.876-0.747$ (b) middle_layer, sigma $-p=0.699-0.520$

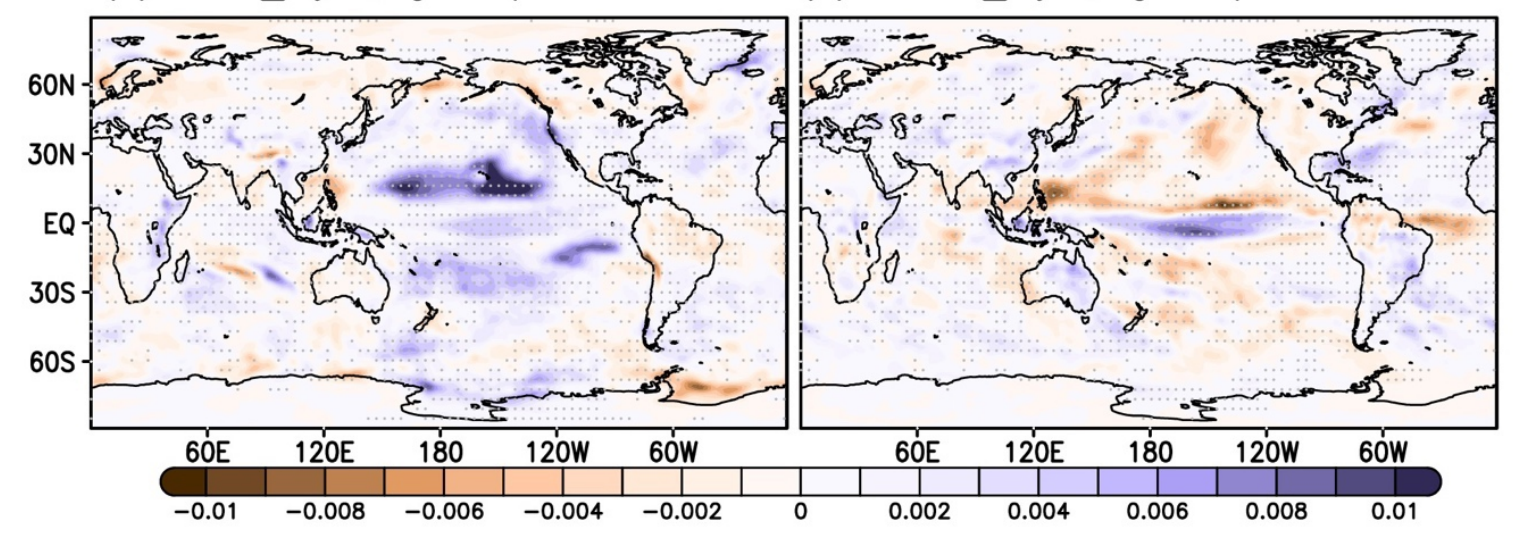

Figure 5. The same as in Figure 4, except for cloud water contents averaged over the levels of (a) 0.8760.747 and (b) $0.699-0.520$ using the hybrid $\sigma-p$ coordinate. 
diff. Reg. (a) $-(c)$ with glb_T

(a) vertical flow $[\mathrm{Pa} / \mathrm{s} / \mathrm{K}]$

(b) air temperature $[\mathrm{K} / \mathrm{K}]$

(c) cloud water $[\mathrm{g} / \mathrm{kg} / \mathrm{K}]$
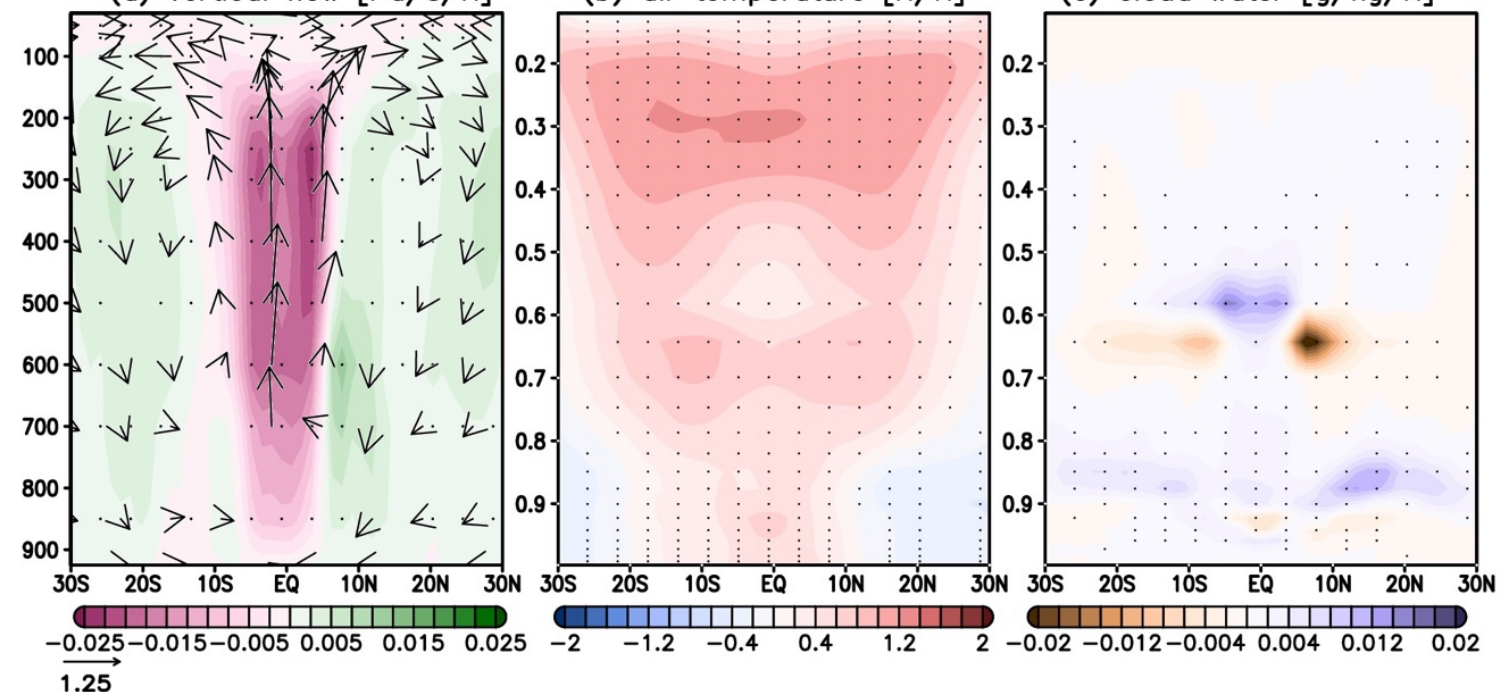

Figure 6. Differences between PFP_large and PFP_small for (a) vertical winds (shading) and meridional circulation winds (vector), (b) air temperature, and (c) cloud water content, zonally averaged over the area shown in Figure 4 (orange rectangle) and regressed onto global mean surface temperature. The vertical components of the vectors in (a) are multiplied by a factor of 100 . The vertical coordinate in (b) and (c) is depicted by the hybrid $\sigma-p$ coordinate. The stippling indicates the $99 \%$ confidence level (derived using the t-test technique). 


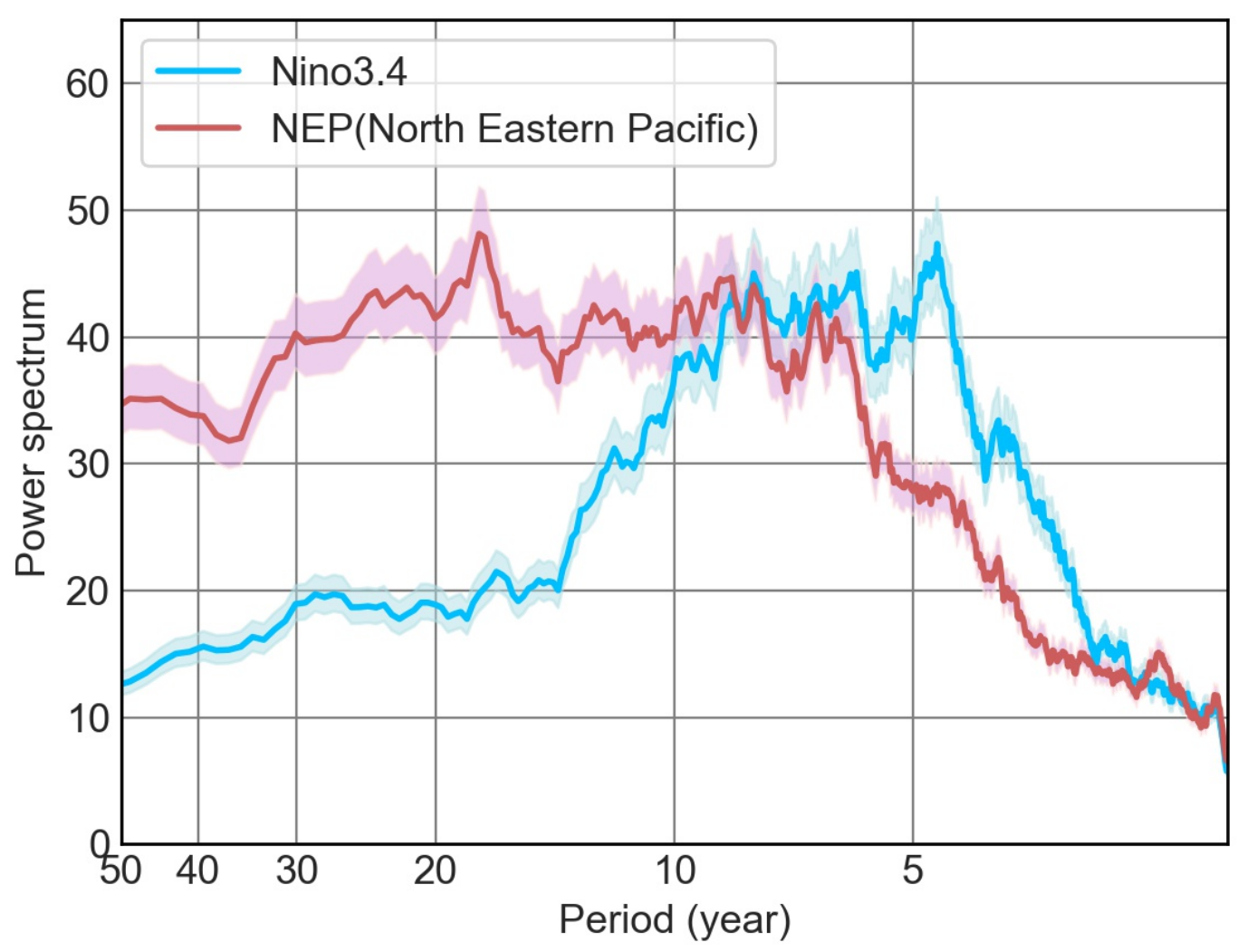

565

566

567

568

569

570

571

572

573

Figure 7. Power spectrums of surface temperature variations averaged over Nino3.4 (blue solid line) and the NEP area (red solid line) designated in Figure 3. Plotted values are smoothed using 30-point running means. Shadings indicate the ranges over $99 \%$ confidence level (derived using the t-test technique). 


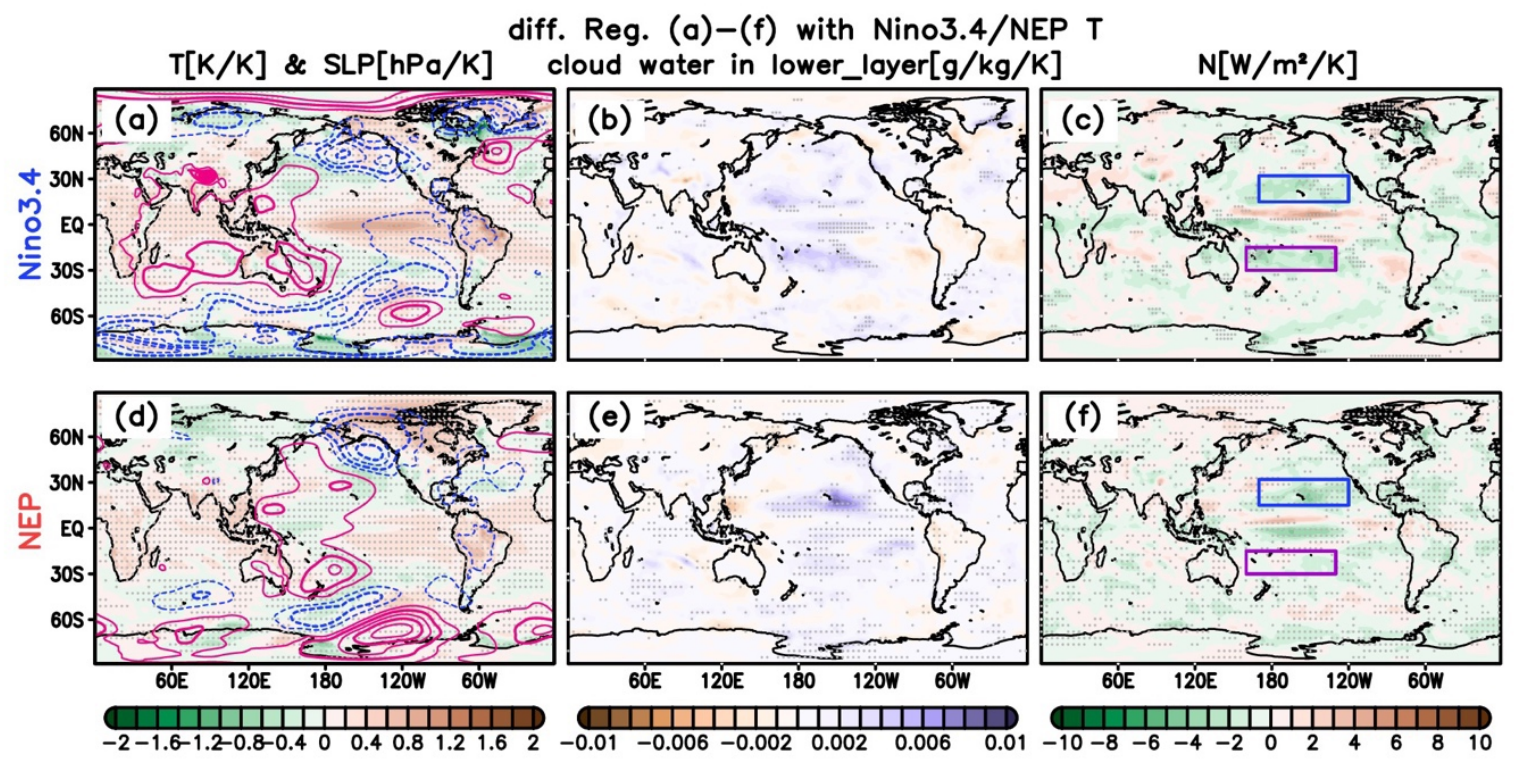

Figure 8. (a) Map of the modified regression value differences between PFP_large and PFP_small of surface temperature and sea level pressure against Nino3.4 SST. Modified regressions of differences to surface temperature averaged over Nino3.4 area, in surface temperature (shading) and sea level pressure (contour, $0.3 \mathrm{hPa} / \mathrm{K}$ interval). Stippling indicates $99 \%$ confidence level (derived using the t-test technique). (b) The same as in panel (a), except for the cloud water content in the lower_layer (same definition mentioned in Figure 5(a). (c) The same as in panel (a), except for the net downward radiation flux at top-of-atmosphere. The blue and purple rectangles were used in the regression analysis (see text 4.3 in detail). (d, e, f) The same as in panels (a, b and c) except for the 